\title{
Special AT-rich DNA-binding protein-1 expression is associated with liver cancer metastasis
}

\author{
DONGMEI WU ${ }^{1 *}$, LIANGTAO ZENG $^{1 *}$, FANRONG LIU $^{1}$, QINGLING ZHONG ${ }^{2}$,

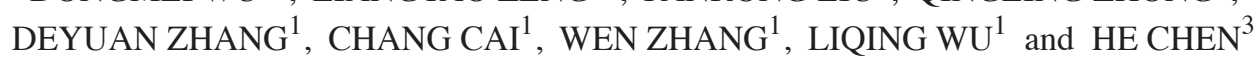 \\ ${ }^{1}$ Department of Pathology, Second Hospital Affiliated to Nanchang University; \\ ${ }^{2}$ Department of Nursing, Medical College of Nanchang University; ${ }^{3}$ Molecular Biology Center, \\ Second Hospital Affiliated to Nanchang University, Nanchang, Jiangxi 330006, P.R. China
}

Received April 22, 2015; Accepted August 25, 2016

DOI: $10.3892 / \mathrm{ol} .2016 .5281$

\begin{abstract}
To aim of the present study was to investigate the association between special AT-rich DNA-binding protein-1 (SATB1) expression and liver cancer metastasis. SATB1 mRNA and protein expression in hepatocellular carcinoma tissues was analyzed by immunohistochemistry, and in two hepatocellular cancer cell lines, MHCC-97H (high metastatic potential) and HepG2 (low metastatic potential), by reverse transcription-polymerase chain reaction and western blot analysis. Transwell migration and wound-healing assays were also performed to investigate the metastasis of liver cancer following upregulation or silencing of SATB1 expression. The results revealed that SATB1 expression was significantly higher in hepatocellular carcinoma tissues compared with carcinoma-adjacent tissues. Furthermore, SATB1 expression was correlated with tumor size, differentiation degree, hemorrhage and/or necrosis, invasion and/or metastases and TNM stage. Both the mRNA and protein expression of SATB1 was higher in MHCC-97H cells than HepG2 cells. In addition, the migration capability of MHCC-97H cells was decreased after SATB1 silencing, whereas the migration capability of HepG2 cells was increased after SATB1 upregulation. SATB1 expression was demonstrated to be positively correlated with liver cancer metastasis. These results indicate that liver cancer metastasis is regulated by SATB1 expression. Thus, immunohistochemical SATB1 expression may present an independent risk factor for the metastasis of liver cancer.
\end{abstract}

Correspondence to: Dr Fanrong Liu, Department of Pathology, Second Hospital Affiliated to Nanchang University, 1 Minde Road, Nanchang, Jiangxi 330006, P.R. China

E-mail: liufanrong@163.com

*Contributed equally

Key words: special AT-rich DNA-binding protein-1, liver cancer, metastasis

\section{Introduction}

Liver cancer is one of the most common malignancies, worldwide, with the highest morbidity rates in China (1). Due to difficult treatment, poor prognosis, relapse and metastasis following surgery and the high mortality rate, liver cancer presents a significant health problem (2). Thus, liver cancer-related genes and their mechanisms of action have received increasing attention in recent years. Notably, special AT-rich DNA-binding protein-1 (SATB1) has been investigated due to its association with tumor growth and metastasis. SATB1 is involved with the growth and differentiation of T cells, as well as tumor growth and metastasis. SATB1 regulates gene transcription and expression by recruiting chromatin remodeling complexes and anchoring specialized DNA sequences, such as nuclear molecular attachment region-binding protein (3-12). A previous study demonstrated that the body, spleen, thymus and lymph nodes of SATB1 gene knockout mice are significantly smaller those of normal mice, and this difference increases with age, resulting in death 3 weeks after birth (7). These results suggest that SATB1 is predominantly expressed in the thymus and that it exhibits an important function in the growth and differentiation of $T$ cells (7). A previous study revealed that SATB1 is involved in the development of tumors and is closely associated with tumor invasion and metastasis by regulating the cell cycle, inducing cell differentiation and inhibiting apoptosis (10). The function of SATB1 has been confirmed in several tumor types, including breast cancer (13-15), epithelial ovarian cancer (16), gastric cancer (17), colorectal carcinoma (18-20), glioma (21), Hodgkin's lymphoma (22), small cell lung cancer $(23)$, prostate cancer $(24,25)$ and liver cancer (26). Furthermore, a previous study has reported that both the mRNA and protein expression of SATB1 are upregulated when compared with carcinoma-adjacent and normal liver tissue (26). SATB1 expression levels are also hypothesized to correlate with tumor size, degree of differentiation, portal invasion, lymph node metastases and hepatitis B virus infection (26). However, the association between SATB1 expression and liver cancer metastasis and metastasis-associated biological behavior, as well as the clinicopathological significance of immunohistochemical SATB1 expression in 
liver cancer remains unclear. In the present study, the function of SATB1 expression in liver cancer was investigated using histology and cytology.

\section{Materials and methods}

Tumor specimens and cell culture. A total of 60 primary hepatocellular carcinoma tissue samples and 60 adjacent normal liver tissue samples were obtained from patients that underwent surgical resection without prior chemotherapy or radiation at the Second Affiliated Hospital of Nanchang University (Nanchang, China) between January 2010 and December 2013 (Table I) after obtaining patient consent. All adjacent normal liver tissues were resected $\geq 1 \mathrm{~cm}$ from the tumor margin. All tissues were fixed in formaldehyde and histopathological classification, according to the World Health Organization Classification of Tumors of the Digestive System (27), was confirmed by hematoxylin and eosin staining. MHCC-97H (high metastatic potential) and HepG2 (low metastatic potential) human liver cancer cell lines were obtained from the Molecular Biology Center of the Second Affiliated Hospital of Nanchang University and were cultured in Dulbecco's modified Eagle's medium containing $15 \%$ fetal bovine serum (Biological Industries Israel, Beit-Haemek, Israel) at $37^{\circ} \mathrm{C}$ in an atmosphere of $5 \% \mathrm{CO}_{2}$ for $48 \mathrm{~h}$. This study was approved by the ethics committee of the Second Affiliated Hospital of Nanchang University.

Immunohistochemistry (IHC). To analyze SATB1 expression, IHC was performed using $10 \%$ formalin-fixed 4- $\mu \mathrm{m}$ tissue sections of hepatocellular carcinoma and adjacent normal liver tissues. The primary antibody used in the present study was anti-SATB1 (clone, EPR3895; 1:100; Epitomics, Burlingame, CA, USA). Horseradish peroxidase-conjugated anti-sheep/rabbit immunoglobulin (Ig)G (cat. no. PV6001; 1:500; Zhongshan Jinqiao Biotechnology Co., Ltd., Beijing, China) was used as the secondary antibody. Stromal lymphocytes served as internal positive controls, with adjacent normal liver tissue and phosphate-buffered saline buffer replacing the primary antibody as a negative control $(16,18,19)$. The estimated percentage of cells exhibiting nuclear SATB1 expression was denoted as negative, weak, moderate or strong (Fig. $1 ;<1 \%$ positive SATB1 expression, negative staining; $1-50 \%$ positive SATB1 expression, weak staining; $51-75 \%$ positive SATB1 expression, moderate staining; $>75 \%$ positive SATB1 expression, strong staining) and the combined nuclear score was calculated by multiplying the fraction of cells with positive SATB1 expression by the intensity (16). Histological staining for tumor size, tumor differentiation, invasion and metastases, $\alpha$-fetoprotein and TNM stage were performed as previously described $(19,26)$.

Reverse transcription-polymerase chain reaction (PCR). Total RNA was extracted from cells using TRIzol reagent (TransGen Biotech, Inc., Beijing, China) according to the manufacturer's protocol. A $0.4 \mu \mathrm{g}$ aliquot of RNA was reverse-transcribed to cDNA using the PrimeScript RT reagent kit (Takara Bio, Dalian, China) in a $20 \mu \mathrm{l}$ volume containing $1 \mu \mathrm{l}$ cDNA. A total of $10 \mu \mathrm{l}$ PCR SuperMix
(TransGen Biotech, Inc.) was used in subsequent reaction using the following primers: Forward, 5'-AGAGGAAGGCTT GGGAGTA-3' and reverse, 5'-GGGCAGCAGAGCTATGTG -3' for SATB1; forward, 5'-TGATGACATCAAGAAGGTGGT GAAG-3 and reverse, 5'-TCCTTGGAGGCCATGTGGGCC A-3' for GAPDH. PCR was performed using a MyCycler ${ }^{\mathrm{TM}}$ Thermal Cycler System (Bio-Rad Laboratories, Hercules, CA, USA) under the following conditions: Amplification at $95^{\circ} \mathrm{C}$ for $5 \mathrm{~min}$, proceeded by 35 cycles at $95^{\circ} \mathrm{C}$ for $1 \mathrm{~min}, 60^{\circ} \mathrm{C}$ for $30 \mathrm{sec}$ and $72^{\circ} \mathrm{C}$ for $30 \mathrm{sec}$, followed by a final extension step at $72^{\circ} \mathrm{C}$ for $10 \mathrm{~min}$. Negative (no cDNA) and reverse transcription (no reverse transcription) controls were used. All experiments were performed in triplicate.

Western blot analysis. Nucleoprotein was extracted from cells using Nuclear-Cytosol Extraction Kit (Applygen Technologies, Inc., Beijing, China). The protein concentration was determined by spectrophotometer (Eppendorf, Hamburg, Germany) at a wavelength of $280 \mathrm{~nm}$. Protein samples $(15 \mu \mathrm{g})$ were separated by $6 \%$ sodium dodecyl sulfate polyacrylamide gel electrophoresis and subsequently transferred to polyvinylidene fluoride membranes, followed by incubation with the primary SATB1 antibody $\left(1: 1,000\right.$; catalog no., EPR3895) at $4^{\circ} \mathrm{C}$ overnight. The membranes were washed with Tris-buffered saline and Tween 20 and incubated with biotinylated anti-rabbit IgG (1:10,000; catalog no., HS101-01) for $1 \mathrm{~h}$ at room temperature. The intensity of the protein bands was analyzed using Image-Pro Plus image analysis software (Media Cybernetics, Rockville, MD, USA)

Transwell migration and wound-healing assays. In vitro Transwell migration and wound-healing assays were performed as described previously $(28,29)$. The cells adhering to the lower surface of the membrane were stained using hematoxylin and eosin, and the number of cells was calculated in 5 random high-power fields using a DM1000 Leica microscope (Leica, Wetzlar, Germany). The areas of interest were analyzed by ImageJ software (National Institutes of Health, Bethesda, MD, USA).

Silencing and upregulation of SATB1 expression. Three silencing plasmids (GV102-SATB1-RNAi (NM_002971): Sequence 1, 5'-AATGCTCTGAAGGACTTAC-3'; sequence 2, 5'-ACTGTCTTACGTGACAGAT-3'; and sequence 3, 5'-TTC CATTTATGATGAGATT-3'), defined as sh1, sh2 and sh3, respectively and a corresponding control (CON036) were purchased from GeneChem Co., Ltd., (Shanghai, China). An overexpression plasmid, GV144-SATB1, defined as HepG2-up and a corresponding control (CON107) were also purchased from GeneChem Co., Ltd. At $80 \%$ confluence, MHCC-97H hepatic carcinoma cells were transfected with GV102-SATB1-RNAi or CON036 using TurboFect transfection reagent (Thermo, USA) and HepG2 hepatic carcinoma cells were transfected with GV144-SATB1 or CON107. Transgene expression was analyzed after 24-48 h.

Statistical analysis. All assays were repeated four times and all in vitro experiments were performed in triplicate. The data are presented as the mean \pm standard error of the mean. The $\chi^{2}$ test was performed to analyze associations between SATB1 
Table I. Association between SATB1 expression and clinicopathological features of 60 hepatocellular carcinoma patients.

\begin{tabular}{|c|c|c|c|c|}
\hline Parameter & Patients, $\mathrm{n}$ & $\begin{array}{l}\text { Positive SATB1 } \\
\text { expression, n (\%) }\end{array}$ & $\begin{array}{l}\text { Negative SATB1 } \\
\text { expression, n (\%) }\end{array}$ & P-value \\
\hline Gender & & & & 1.000 \\
\hline Male & 45 & $30(66.67)$ & $15(33.33)$ & \\
\hline Female & 15 & $10(66.67)$ & $5(33.33)$ & \\
\hline Age, years & & & & 0.232 \\
\hline$\geq 55$ & 18 & $14(77.78)$ & $4(22.22)$ & \\
\hline$<55$ & 42 & $26(61.90)$ & $16(38.10)$ & \\
\hline Tumor number & & & & 0.839 \\
\hline$>1$ & 17 & $11(64.71)$ & $6(35.29)$ & \\
\hline 1 & 43 & $29(67.44)$ & $14(32.56)$ & \\
\hline Tumor size, $\mathrm{cm}$ & & & & 0.001 \\
\hline$\geq 5$ & 36 & $30(83.33)$ & $6(16.67)$ & \\
\hline$<5$ & 24 & $10(41.67)$ & $14(58.33)$ & \\
\hline Tumor differentiation & & & & 0.000 \\
\hline Moderate and poor & 40 & $33(82.50)$ & $7(17.50)$ & \\
\hline Well & 20 & $7(35.00)$ & $13(65.00)$ & \\
\hline AFP, ng/ml & & & & 0.449 \\
\hline$\geq 100$ & 22 & $16(72.73)$ & $6(27.27)$ & \\
\hline$<100$ & 38 & $24(63.16)$ & $14(36.84)$ & \\
\hline Hemorrhage and/or necrosis & & & & 0.010 \\
\hline Present & 26 & $24(92.31)$ & $2(7.69)$ & \\
\hline Absent & 34 & $16(47.06)$ & $18(52.94)$ & \\
\hline Invasion and/or metastases & & & & 0.022 \\
\hline Present & 19 & $17(89.47)$ & $2(10.53)$ & \\
\hline Absent & 41 & $23(56.10)$ & $18(43.90)$ & \\
\hline TNM stage & & & & 0.008 \\
\hline I-II & 22 & $7(31.80)$ & $15(68.20)$ & \\
\hline III-IV & 38 & $33(86.84)$ & $5(13.16)$ & \\
\hline
\end{tabular}

SATB1, special AT-rich DNA-binding protein-1; AFP, $\alpha$-fetoprotein.
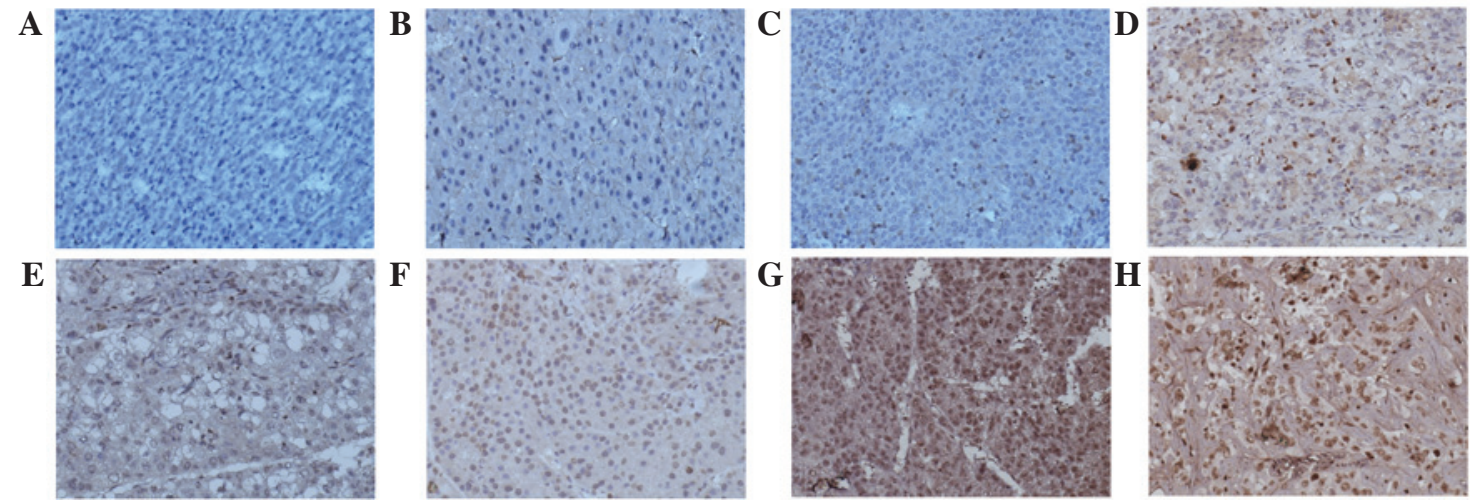

Figure 1. Immunohistochemical SATB1 staining in hepatocellular carcinoma and carcinoma-adjacent tissues. SATB1 was predominantly localized in the nucleus with a low level of expression in the perinuclear cytoplasm. (A) Negative SATB1 expression in normal liver tissue. (B) Negative, (C and D) weak, (E and F) moderate and $(\mathrm{G}$ and $\mathrm{H})$ strong SATB1 staining in tumor cells. Magnification, x200. SATB1, special AT-rich DNA-binding protein-1.

expression (nuclear score) and hepatocellular carcinoma-associated biological parameters. The Student's $t$-test was used to compare differences between groups. All statistical analyses were performed using SPSS 13.0 (SPSS, Inc., Chicago, IL, USA). $\mathrm{P}<0.05$ was considered to indicate a statistically significant difference. 
A

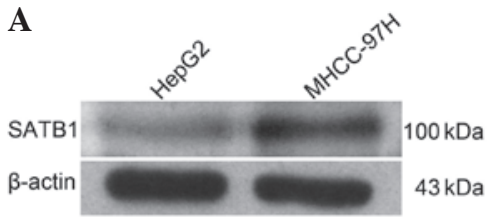

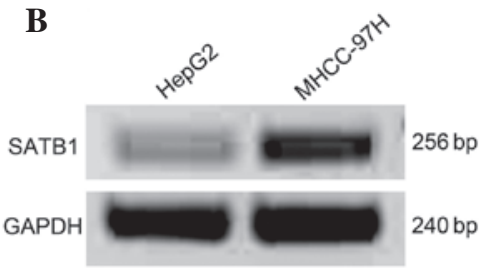

C

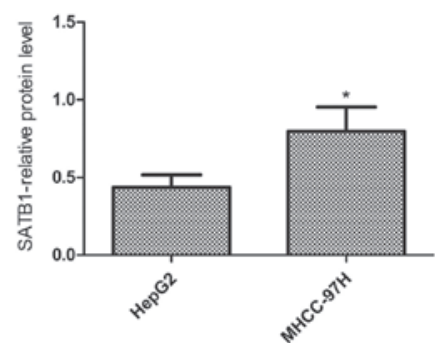

Figure 2. SATB1 mRNA and protein levels in MHCC-97H (high metastatic potential) and HepG2 (low metastatic potential) liver cancer cell lines were assessed by western blot analysis and polymerase chain reaction. SATB1 (A) protein and (B) mRNA expression was higher in MHCC-97H cells than HepG2 cells. $\beta$-actin and GAPDH were used as loading controls. (C) Quantification of western blot analysis revealed that SATB1 protein expression was significantly higher in MHCC-97H cells compared with HepG2. ${ }^{*} \mathrm{P}<0.05$. Data are presented as the mean \pm standard error of the mean of three independent experiments. ATB1, special AT-rich DNA-binding protein-1; GAPDH, glyceraldehyde 3-phosphate dehydrogenase.

A

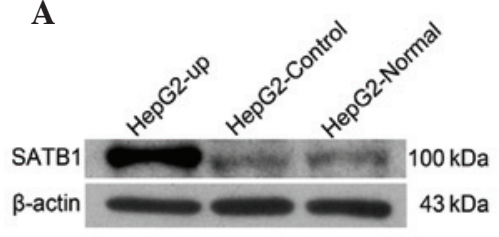

C

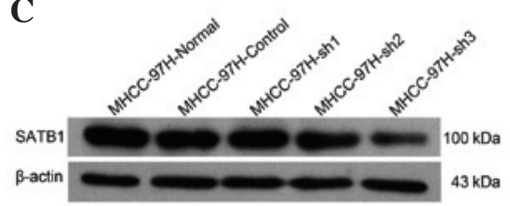

B

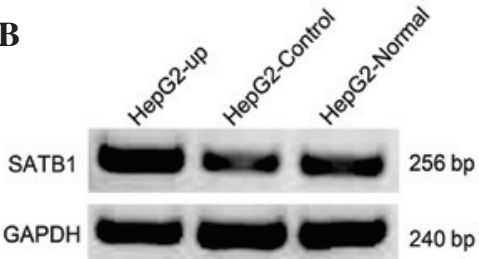

D

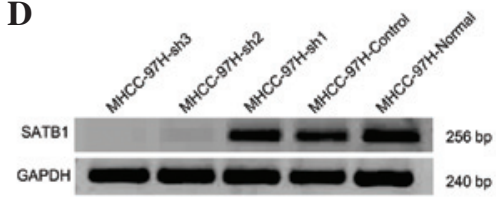

E

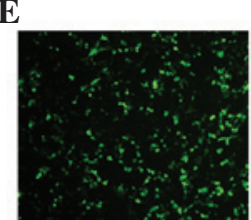

MHCC-97H-sh3

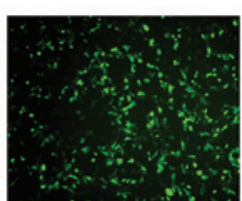

MHCC-97H-Control

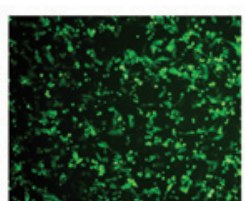

HepG2-Control

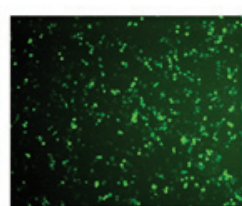

HepG2-up
$\mathbf{F}$

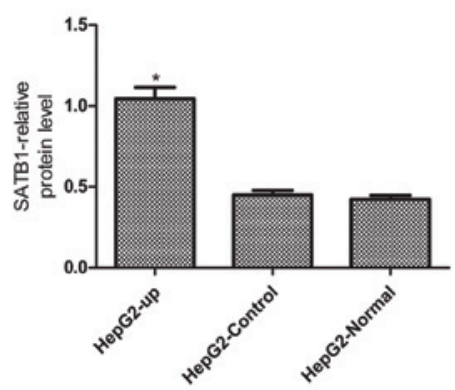

G

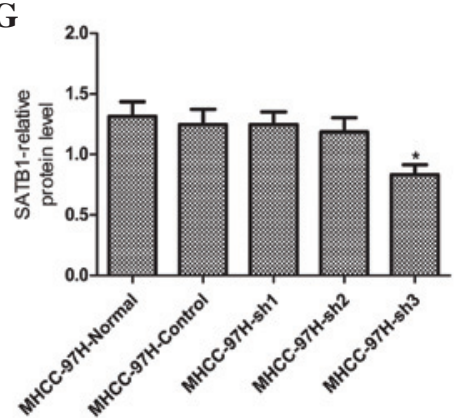

Figure 3. SATB1 is upregulated in human liver cancer cell lines HepG2 (low metastatic potential) and silenced in MHCC-97H (high metastatic potential), (A) Upregulation of SATB1 protein expression in HepG2 cells. (B) Upregulation of SATB1 mRNA expression in HepG2. (C) SATB1 protein expression in MHCC-97H cells after silencing. (D) SATB1 mRNA expression in MHCC-97H after silencing. (E) Immunofluorescence images of SATB1 expression in HepG2 and MHCC-97H cells (magnification, x200). (F) Relative SATB1 protein expression was significantly increased in HepG2-up cells compared with HepG2-control and HepG2-normal cells. (G) Relative SATB1 protein expression was significantly decreased in MHCC-97H-sh3 cells when compared with MHCC-97H-Normal, MHCC-97H-Control, MHCC-97H-sh1 and MHCC-97H-sh2 cells. Data are presented as the mean \pm standard error of the mean of three independent experiments. SATB1, special AT-rich DNA-binding protein-1; GAPDH, glyceraldehyde 3-phosphate dehydrogenase. ${ }^{*} \mathrm{P}<0.05$.

\section{Results}

SATB1 expression is positively correlated with metastasis in human liver cancer tissues and cell lines. As shown in Fig. 1, SATB1 was predominantly localized in the nucleus with a low level of expression in the perinuclear cytoplasm, in accordance 


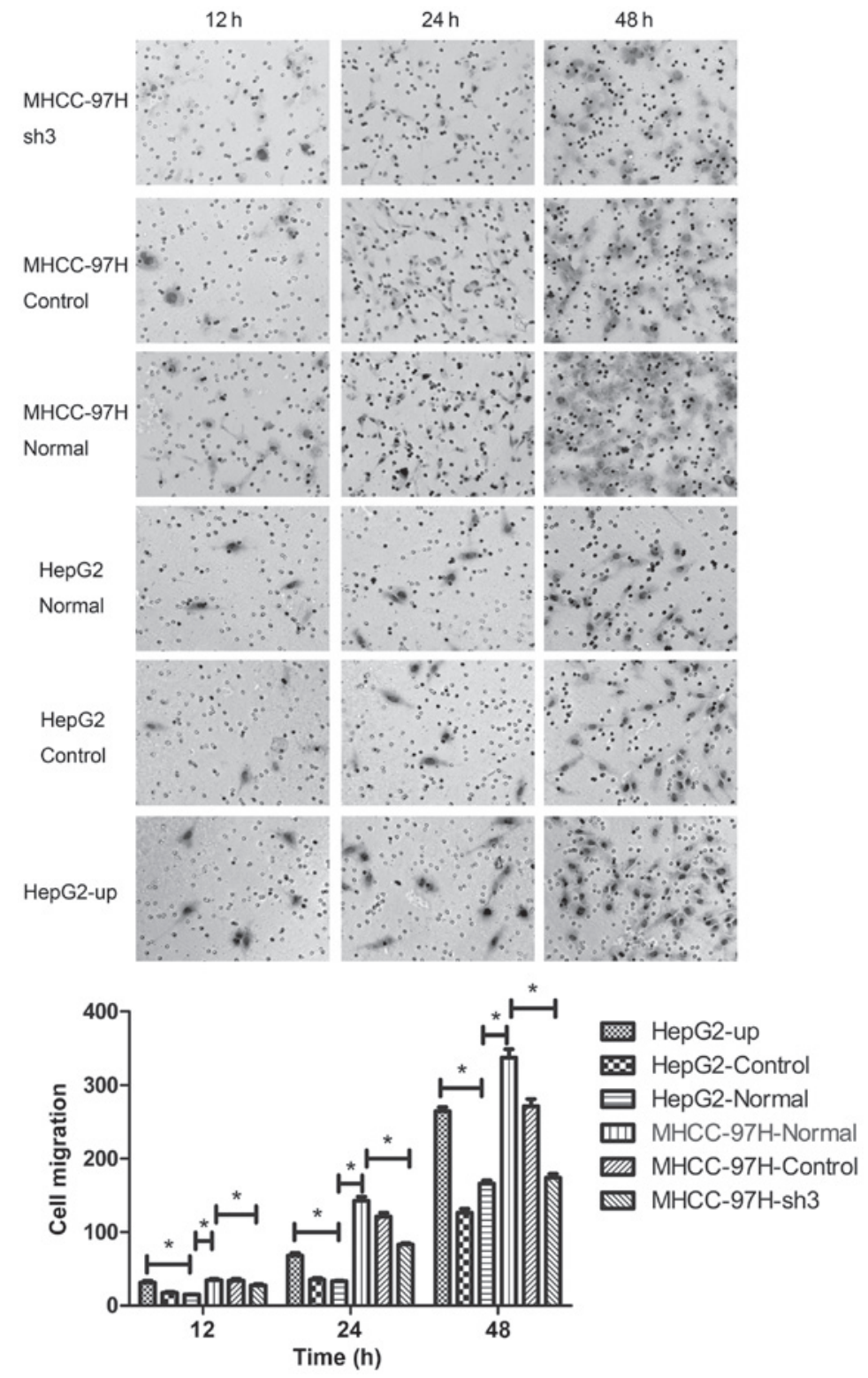

Figure 4. Metastasis of liver cancer cell lines is positively correlated with special AT-rich DNA-binding protein-1 expression levels. The number of migrating HepG2 cells increased following upregulation of SATB1 expression and the number of migrating MHCC-97H cells decreased after silencing of SATB1 expression. In vitro cell migration capability was analyzed by Transwell migration assay and images of cells were captured using an inverted microscope (x200 magnification). Cells adhering to the lower surface of the membrane were stained with hematoxylin and eosin and the number of cells were calculated in 5 high-power fields ${ }^{*} \mathrm{P}<0.05$. Data are presented as the mean \pm standard error of the mean of three independent experiments.

with that reported previously (19). Absent or extremely weak SATB1 expression was identified in 50/60 (83.33\%) carcinoma-adjacent tissues (Fig. 1A). Positive SATB1 expression was observed in 40/60 (66.67\%) hepatocellular carcinoma tissues, which ranged from weak to strong in intensity (Fig. 1C-H). SATB1 expression was significantly higher in hepatocellular carcinoma tissues compared with carcinoma-adjacent tissues $(\mathrm{P}<0.0001)$. In addition, the percentage of positive SATB1 expression in hepatocellular carcinoma samples with tumors $\geq 5 \mathrm{~cm}$, moderately and poorly-differentiated tumors, hemorrhage and/or necrosis, invasion and/or metastases and TNM stages III-IV were 83.33, 82.50, 84.62, 85.71 and 78.95\%, respectively (Table I), suggesting that SATB1 expression is associated with tumor size, differentiation degree, hemorrhage and/or necrosis, invasion and/or metastases and TNM stage $(\mathrm{P}<0.05$; Table I).
SATB1 mRNA and protein expression levels were also analyzed in two different liver cancer cell lines, MHCC-97H (high metastatic potential) and HepG2 (low metastatic potential) $(30,31)$. SATB1 mRNA and protein expression was higher in the MHCC-97H cell line than the HepG2 cell line ( $\mathrm{P}=0.002$ and $\mathrm{P}=0.001$, respectively). It was also observed that SATB1 expression is correlated with metastasis in human liver cancer tissues and cell lines ( $\mathrm{P}<0.05$; Fig. 2).

Silencing and upregulation of SATB1 expression in human liver cancer cell lines. The MHCC-97H (high SATB1 expression) and HepG2 (low SATB1 expression) cell lines were selected to investigate the effects of SATB1 gene silencing and overexpression, respectively, in order to further investigate the association between SATB1 expression and liver cancer metastasis (Fig. 3). SATB1 mRNA and protein levels were increased 


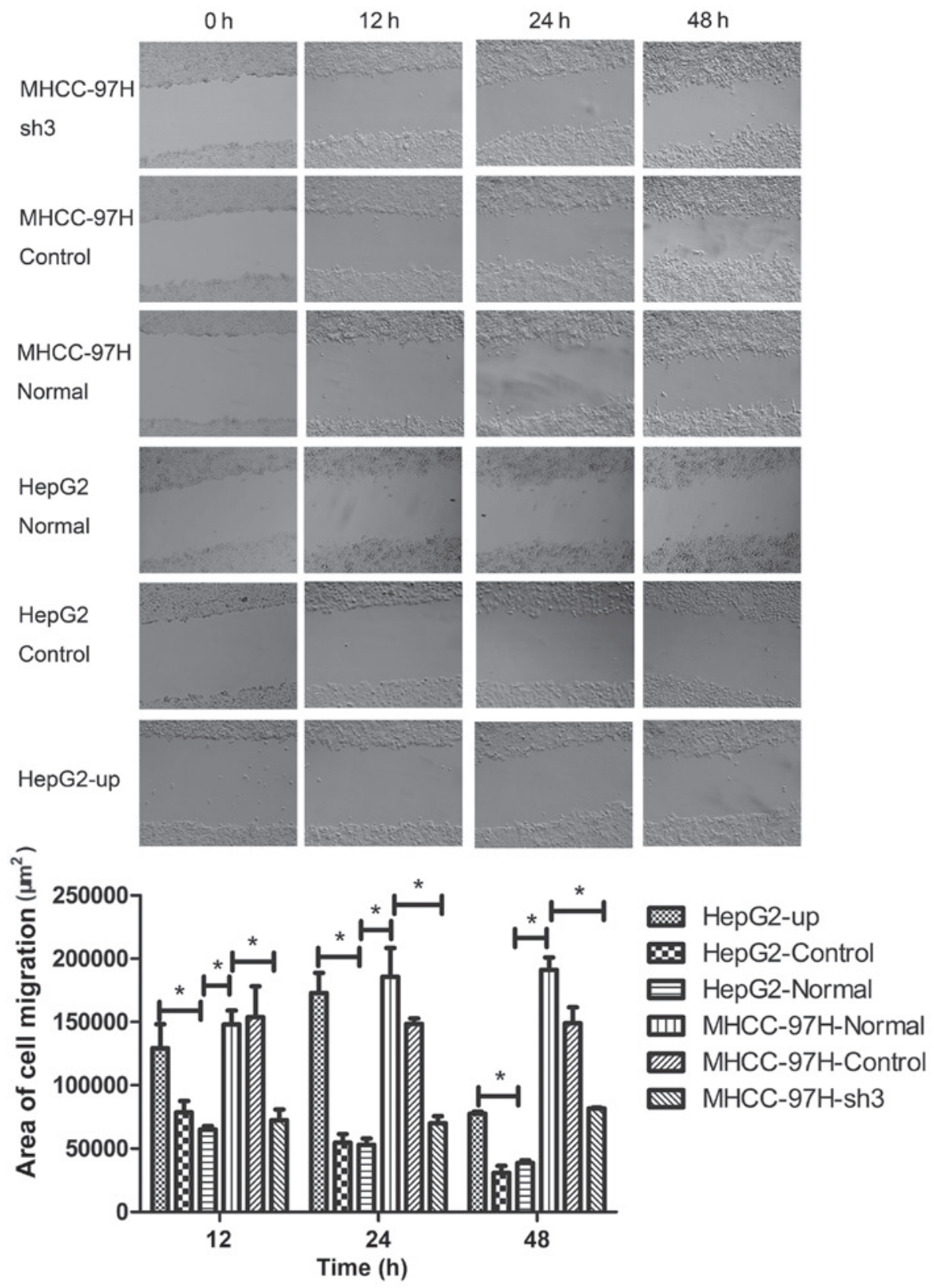

Figure 5. Metastasis of liver cancer cell lines is positively correlated with special AT-rich DNA-binding protein-1 expression. In vitro cell migration capability was analyzed by wound-healing assay and images of cells were captured using an inverted microscope (x200x magnification). The area of interest was analyzed using ImageJ software. $\mathrm{P}<0.05$. Data are presented as the mean \pm standard error of the mean of three independent experiments.

significantly in HepG2 cells following transfection with the HepG2-up plasmid, which exhibited a transfection efficiency of $80 \%$, however, no significant differences in SATB1 mRNA or protein expression levels were identified in the cells transfected with the control CON107 plasmid, which exhibited a transfection efficiency of $90 \%$ (Fig. 3A, B and F; P<0.05). MHCC-97H cells were transfected with 3 silencing plasmids, sh1, sh2 and sh3, or the corresponding control CON036 plasmid. The results revealed that SATB1 protein levels were significantly lower in the sh3-transfection group, which exhibited a transfection efficiency of $70 \%$ compared with the sh1, sh2 and control CON036-transfected groups, which exhibited a transfection efficiency of $80 \%$ (Fig. 3C). No significant differences in SATB1 protein expression were identified in the sh1, sh2 and CON036 groups compared with normal MHCC-97H cells (Fig. 3C and G; P<0.05). SATB1 mRNA expression was significantly lower in the sh2 and sh3-transfected groups compared with the normal MHCC-97H (Fig. 3D; P<0.05), while no significant differences in SATB1 mRNA expression were identified in the sh1 and CON036-transfection groups compared with normal MHCC-97H cells. Therefore, the sh3 silencing plasmid was selected to transfect MHCC-97H cells for subsequent experiments.

Metastasis of liver cancer MHCC-97H and HepG2 cell lines is positively correlated with SATB1 expression. As our previous experiments had indicated that SATB1 expression was associated with the metastasis of liver cancer, the biological behavior of MHCC-97H and HepG2 cells was assessed using Transwell migration and wound-healing assays. The 
number of cells adhering to the lower surface of the membrane in the MHCC-97H liver cancer cell line was significantly higher compared than the HepG2 cell line $(\mathrm{P}<0.05$; Fig. 4). The number of cells adhering to the lower surface of the membrane decreased significantly in the MHCC-97H cell line following transfection with the sh3 plasmid (Fig. 4; $\mathrm{P}<0.05$ ). By contrast, the number of cells adhering to the lower surface of the membrane in the HepG2 cell line increased significantly compared with the normal group following transfection with the HepG2-up plasmid (Fig. 4; $\mathrm{P}<0.05$ ). No significant differences in migration capability were identified between the control groups CON036 and CON107 and the corresponding normal groups (Fig. 4; P>0.05). Wound-healing assays were performed and the area of cell migration of the scratch area was used to determine the migration of cancer cell lines. The area of cell migration was greater in the MHCC-97H liver cancer cell line than in the HepG2 cell line (Fig. 5; $\mathrm{P}<0.05$ ). The area of cell migration of the scratch area decreased significantly compared with the normal group after the sh3 plasmid was transfected into the MHCC-97H liver cancer cell line (Fig. $5 ; \mathrm{P}<0.05$ ). The area of cell migration of the scratch area increased significantly in the HepG2 liver cancer cell line following transfection with the HepG2-up plasmid when compared with the normal group (Fig. 5; P<0.05). No significant differences in the area of cell migration were identified between the control groups CON036 and CON107 and the corresponding normal groups (Fig. 5; $\mathrm{P}<0.05$ ).

\section{Discussion}

The results of the present study revealed that SATB1 mRNA expression was higher in MHCC-97H cells (high metastatic potential) than HepG2 cells (low metastatic potential) and that the metastatic potential of liver cancer cells was correlates with increased SATB1 expression. Han et al (13) reported that SATB1 expression may used as an independent factor of poor prognosis and demonstrated that SATB1 correlated with poor prognosis, even in breast cancer patients that exhibited low immunohistochemical expression levels. Furthermore, Tu et al (26) demonstrated that SATB1 promotes growth and metastasis of liver cancer in vitro and in vivo via promotion of cell cycle progression, apoptosis inhibition and induction of epithelial-mesenchymal transition. However, in the present study, the association between SATB1 expression and liver cancer metastasis was demonstrated by both SATB1 up- and downregulation in biological behavior assays. The results revealed that SATB1 expression positively correlates with the metastasis of liver cancer, in accordance with previously reported data (16-26). At present, an increasing number of patients with liver cancer are diagnosed at an early stage as a result of the advent of precision instruments, including ultrasonic imaging and the development of fine-needle puncture. In addition, histopathological classification and immunohistochemical results provided by specific antibodies are easier to obtain than results following surgery, which is the typical treatment route in cases of liver cancer. The surgical approach requires the expertise of a clinical pathologist to improve the diagnostic level possible with a limited tissue sample, thus improving the utility of the diagnosis for clinical treatment. In the present study, a correlation was identified between SATB1 expression and liver cancer metastasis. Furthermore, SATB1 expression was associated with tumor size, differentiation degree, hemorrhage and/or necrosis, invasion and/or metastases and TNM stage, which may are often considered as prognostic factors during clinicopathological diagnosis. Therefore, future studies using a larger sample size with adequate clinical follow-up data are required. The aim of the present study was to investigate the association between SATB1 expression and metastasis of liver cancer. The results indicate that SATB1 expression may present a prognostic factor for liver cancer, and thus these findings may lead to improved guidance for clinical treatment. The results indicate that SATB1 may present a novel target for liver cancer treatment.

\section{References}

1. Parkin DM: Global cancer statistics in the year 2000. Lancet Oncol 2: 533-543, 2001

2. Li G, Yang D, Li X, Zhong K, Liu X, Bi M, Liu Y, Liao X and Lin L: Expression of SATB1 in hepatocellular carcinoma cell lines with different invasive capacities. Nan Fang Yi Ke Da Xue Xue Bao 32: 986-994, 2012 (In Chinese).

3. Xu L, Deng HX, Xia JH, Yang Y, Fan CH, Hung WY and Siddque T: Assignment of SATB1 to human chromosome band 3 p23 by in situ hybridization. Cytogenet Cell Genet 77: 205-206, 1997.

4. Dickinson LA, Joh T, Kohwi Y and Kohwi-Shigematsu T: A tissue-specific MAR/SAR DNA-binding protein with unusual binding site recognition. Cell 70: 631-645, 1992.

5. Wen J, Huang S, Rogers H, Dickinson LA, Kohwi-Shigematsu T and Noguchi CT: SATB1 family protein expressed during early erythroid differentiation modifies globin gene expression. Blood 105: 3330-3339, 2005.

6. Kumar PP, Purbey PK, Ravi DS, Mitra D and Galande S: Displacement of SATB1-bound histone deacetylase 1 corepressor by the human immunodeficiency virus type 1 transactivator induces expression of interleukin-2 and its receptor in T cells. Mol Cell Biol 25: 1620-1633, 2005.

7. Yasui D, Miyano M, Cai S, Varga-Weisz $P$ and Kohwi-Shigematsu T: SATB1 targets chromatin remodelling to regulate genes over long distances. Nature 419: 641-645, 2002 .

8. Wang Z, Yang X, Chu X, Zhang J, Zhou H, Shen Y and Long J: The structural basis for the oligomerization of the N-terminal domain of SATB1. Nucleic Acids Res 40: 4193-4202, 2012.

9. Kumar PP, Bischof O, Purbey PK, Notani D, Urlaub H, Dejean A and Galande S: Functional interaction between PML and SATB1 regulates chromatin-loop architecture and transcription of the MHC class I locus. Nat Cell Biol 9: 45-56, 2007.

10. Galande S, Purbey PK, Notani D and Kumar PP: The third dimension of gene regulation: Organization of dynamic chromatin loopscape by SATB1. Curr Opin Genet Dev 17: 408-414, 2007.

11. Beyer M, Thabet Y, Müller RU, Sadlon T, Classen S, Lahl K, Basu S, Zhou X, Bailey-Bucktrout SL, Krebs W, et al: Repression of the genome organizer SATB1 in regulatory $\mathrm{T}$ cells is required for suppressive function and inhibition of effector differentiation. Nat Immunol 12: 898-907, 2011.

12. Notani D, Gottimukkala KP, Jayani RS, Limaye AS, Damle MV, Mehta S, Purbey PK, Joseph J and Galande S: Global regulator SATB1 recruits beta-catenin and regulates $\mathrm{T}(\mathrm{H}) 2$ differentiation in Wnt-dependent manner. PLoS Biol 8: e1000296, 2010.

13. Han HJ, Russo J, Kohwi Y and Kohwi-Shigematsu T: SATB1 reprogrammes gene expression to promote breast tumour growth and metastasis. Nature 452: 187-193, 2008.

14. Hanker LC, Karn T, Mavrova-Risteska L, Ruckhäberle E, Gaetje R, Holtrich U, Kaufmann M, Rody A and Wiegratz I: SATB1 gene expression and breast cancer prognosis. Breast 20: 309-313, 2011.

15. Li QQ, Chen ZQ, Cao XX, Xu JD, Xu JW, Chen YY, Wang WJ, Chen Q, Tang F, Liu XP and Xu ZD: Involvement of $\mathrm{NF}-\kappa \mathrm{B} / \mathrm{miR}-448$ regulatory feedback loop in chemotherapy-induced epithelial-mesenchymal transition of breast cancer cells. Cell Death Differ 18: 16-25, 2011. 
16. Nodin B, Hedner C, Uhlén M and Jirström K: Expression of the global regulator SATB1 is an independent factor of poor prognosis in high grade epithelial ovarian cancer. J Ovarian Res 5: 24, 2012.

17. Sun F, Lu X, Li H, Peng Z, Wu K, Wang G and Tong Q: Special AT-rich sequence binding protein 1 regulates the multidrug resistance and invasion of human gastric cancer cells. Oncol Lett 4: 156-162, 2012

18. Nodin B, Johannesson H, Wangefjord S, O'Connor DP, Lindquist KE, Uhlén M, Jirström K and Eberhard J: Molecular correlates and prognostic significance of SATB1 expression in colorectal cancer. Diagn Pathol 7: 115, 2012.

19. Zhang J, Zhang B, Zhang X, Sun Y, Wei X, McNutt MA, Lu S, Liu Y, Zhang D, Wang M, et al: SATB1 expression is associated with biologic behavior in colorectal carcinoma in vitro and in vivo. PloS One 8: e47902, 2013.

20. Meng WJ, Yan H, Zhou B, Zhang W, Kong XH, Wang R, Zhan L, Li Y,Zhou ZG and Sun XF: Correlation of SATB1 overexpression with the progression of human rectal cancer. Int J Colorectal Dis 27: 143-150, 2012

21. Chu SH, Ma YB, Feng DF, Zhang H, Zhu ZA, Li ZQ and Jiang PC: Upregulation of SATB1 is associated with the development and progression of glioma. J Transl Med 10: 149, 2012.

22. Liu Y, van den Berg A, Veenstra R, Rutgers B, Nolte I, van Imhoff G, Visser L and Diepstra A: PML nuclear bodies and SATB1 are associated with HLA class I expression in EBV+ Hodgkin lymphoma. PloS One 8: e72930, 2013.

23. Huang B, Zhou H, Wang X and Liu Z: Silencing SATB1 with siRNA inhibits the proliferation and invasion of small cell lung cancer cells. Cancer Cell Int 13: 8, 2013.
24. Shukla S, Sharma H, Abbas A, MacLennan GT, Fu P, Danielpour D and Gupta S: Upregulation of SATB1 is associated with prostate cancer aggressiveness and disease progression. PloS One 8: e53527, 2013.

25. Mao L, Yang C, Wang J, Li W, Wen R, Chen J and Zheng J: SATB1 is overexpressed in metastatic prostate cancer and promotes prostate cancer cell growth and invasion. J Transl Med 11: 111, 2013.

26. Tu W, Luo M, Wang Z, Yan W, Xia Y, Deng H, He J, Han P and Tian D: Upregulation of SATB1 promotes tumor growth and metastasis in liver cancer. Liver Int 32: 1064-1078, 2012.

27. Bosman FT, Carneiro F, Hruban RH and Theise ND. WHO Classification of Tumours of the Digestive System. 4th edition. World Health Organization, pp417, 2010.

28. Liang CC, Park AY and Guan JL: In vitro scratch assay: A convenient and inexpensive method for analysis of cell migration in vitro. Nat Protoc 2: 329-333, 2007.

29. Obermajer N, Doljak B and Kos J: Cytokeratin 8 ectoplasmic domain binds urokinase-type plasminogen activator to breast tumor cells and modulates their adhesion, growth and invasiveness. Mol Cancer 8: 88, 2009.

30. Cheng J, Huo DH, Kuang DM, Yang J, Zheng L and Zhuang SM: Human macrophages promote the motility and invasiveness of osteopontin-knockdown tumor cells. Cancer Res 67: 5141-5147, 2007.

31. Li Y, Tang Y, Ye L, Liu B, Liu K, Chen J and Xue Q: Establishment of a hepatocellular carcinoma cell line with unique metastatic characteristics through in vivo selection and screening for metastasis-related genes through cDNA microarray. J Cancer Res Clin Oncol 129: 43-51,2003. 